\title{
Extraction of 10-30-Day Stable Components from a Boreal Atmosphere during ENSO Phases
}

\author{
Kuo Wang, ${ }^{1,2,3}$ Guolin Feng, ${ }^{2}$ Yuxing Zeng, ${ }^{3}$ and Zhengquan $\mathrm{Li}^{1}$ \\ ${ }^{1}$ Zhejiang Climate Center, Zhejiang Meteorological Bureau, Hangzhou 310017, China \\ ${ }^{2}$ Laboratory for Climate Studies, National Climate Center, China Meteorological Administration, Beijing 100081, China \\ ${ }^{3}$ College of Atmospheric Sciences, Lanzhou University, Lanzhou 730000, China \\ Correspondence should be addressed to Guolin Feng; fenggl@cma.gov.cn
}

Received 27 July 2015; Accepted 22 October 2015

Academic Editor: Yi Wang

Copyright (C) 2015 Kuo Wang et al. This is an open access article distributed under the Creative Commons Attribution License, which permits unrestricted use, distribution, and reproduction in any medium, provided the original work is properly cited.

\begin{abstract}
Distinguishing the predictable 10-30-day stable components (STs) in the actual atmosphere has been important in atmospheric science research. In this study, a new method for extracting 10-30-day STs was developed with the use of historical observations. We extracted and analyzed 10-30-day STs via statistical extrapolation tests. The results show that the STs are maintained uniformly at the intraseasonal time scale; the overall trends in the atmospheric motion are revealed. Comparisons between pentad-by-pentad changes in the explained variances of the 10-30-day STs under ENSO phases show that the explained variance transmission attenuation trends for El Niño and La Niña years are weaker and more continuous than those of neutral years. Data for 10-30day STs can remain continuous and stable from one month to the next. The proposed method and results present a new means of extracting predictable STs from the atmosphere using historical data.
\end{abstract}

\section{Introduction}

In recent years, extended-range weather forecasts have been significantly improved with scientific and technological developments. However, because the atmosphere functions as a forced dissipative nonlinear system, its predictability is sensitive to initial conditions. The upper limit of synoptic weather predictability is known to extend to approximately two weeks [1-3]. However, predictions that exceed this upper limit are not necessarily void of predictable components [4]. The atmosphere includes planetary-scale activity, such as subtropical highs and polar vortexes, that exhibit characteristic time scales that are much longer than those of synoptic systems, and quasi biweekly (10-20 days) and intraseasonal (30-60 days) oscillations are also present in the atmosphere [5-7]. In large-scale circulation patterns, which are not sensitive to initial conditions in specific areas, external forcing is important. The predictability of the average largescale atmospheric circulation is significantly higher than that of the small-scale atmospheric circulation, and predictability exceeds two weeks [8-10].
Interannual climate variability consists of climate signals and noise. Climate signals are variations forced by slowly varying anomalous boundary conditions of the climate system [11-13]. When the proportion of the climate signal variability is high enough to overcome the destruction effects of noise, the climate anomaly may exhibit a particular degree of predictability [14]. A number of slowly varying processes of the atmospheric evolution exceed the level of weather noise. These processes are linked to large-scale atmospheric motion over a time scale of a few weeks, and they last for a much longer period than those estimated based on nonlinear fluid dynamics [15]; this characteristic suggests that atmospheric motion on an extended-range (10-30 days) time scale has predictability $[16,17]$. In turn, stable atmospheric components can be objectively forecasted over a 10-30-day time scale [18].

Given the varying predictability for different meteorological characteristics over the same time period, Chou and $\mathrm{Xu}$ [19] recommended dividing a meteorological variable into two components. A numerical model state variable includes predictable STs on the extended-range (10-30 days) time scale 
in addition to unpredictable chaotic components; predictable and chaotic components can be then forecasted using various methods. Under the same initial and extraneous forcing, a system with a larger spatial/temporal scale presents greater predictability overall. In weather or climate predictions at different spatial/temporal scales, the stable and predictable components should be considered. Determining major features of STs may further improve the skill of weather system prediction.

Based on previous studies and statistical analyses of historical observations, we found that components with high explained variance and long durations exist within a time scale of 10-30 days in the Northern Hemisphere, and we define these as 10-30-day STs. In this study, we describe a means of extracting and defining 10-30-day STs and use historical data to test their informational transmission timeliness from one month to the next. To overcome limitations of daily weather forecast predictability, the pentad average of daily data is calculated to reveal significant STs over 10-30 days in the atmosphere. This work proposes a new method for use in intraseasonal oscillation studies and serves as an important reference for extended-range weather forecasting.

\section{Data and Method}

2.1. Data. The data used in this study was issued by the National Oceanic and Atmospheric Administration (NOAA) and the National Centers for Environmental Prediction/Department of Energy (NCEP/DOE) Reanalysis 2 daily mean data from 1979 to 2013 [20]. The dataset had a $2.5^{\circ} \times 2.5^{\circ}$ horizontal resolution. To unify the data, February 29th (leap year) was removed. We used six pentads for each month, in which the first five constitute the average over five days and the last constitutes the average for the remaining days of that month.

2.2. Method. When the initial field $X_{0}$ and external forcing $F$ values are given, the predictable time $T_{p}$ of the climate system with a spatial scale of $D$ (three-dimensional) and a time scale of $T$ satisfies the following relationship [21]:

$$
T_{p}=T_{p}\left(D \times T ; X_{0}, F\right) .
$$

Under the same initial conditions and external forcing and for a specific forecast time $T_{p}$ that corresponds to a critical scale $D$, the relationships satisfy (1). STs of the system are such that spatial and temporal scales $\left(D_{i} \times T\right)$, which are beyond the spatial and temporal limitation of the predictability of system for a given time scale, satisfy the following inequalities:

$$
D \leq D_{i}, T_{p} \leq T_{p}\left(D_{i} \times T ; X_{0}, F\right) .
$$

Chaotic components of the system are such at a scale of $\left(D_{i} \times\right.$ $T$ ) which satisfies the following inequalities:

$$
D_{i} \leq D, T_{p}\left(D_{i} \times T ; X_{0}, F\right) \leq T_{p} .
$$

Furthermore, we can process STs as follows:

$$
\left(D_{i} \times T\right)=\overline{\left(D_{i} \times T\right)}+\left(D_{i} \times T\right)^{\prime},
$$

where $\left(D_{i} \times T\right)$ denotes STs with a spatial-temporal scale of $\left(D_{i} \times T\right), \overline{\left(D_{i} \times T\right)}$ represents the multiyear climatically averaged STs, and $\left(D_{i} \times T\right)^{\prime}$ stands for the perturbation of STs. In other words, STs can be regarded as the climatically averaged STs plus the perturbation of STs.

Classic predictability studies show that when the prediction error of a prediction is less than the average predicted climate change and when the prediction of individual processes can provide additional information beyond that given by prediction statistics (climate), the corresponding period may be deemed the predictability time limit of the process studied. Therefore, in specific predictions, the predictable aspect of a system forms the stable component, while the unpredictable aspect forms the chaos component. STs must be examined to identify their main characteristics and to improve system prediction levels $[22,23]$.

EOF decomposition is used in this study to depict the features of meteorological fields, and it is useful to simplify the complex in calculation. The basic premise of EOF is that a series of meteorological fields are decomposed into linear combinations of eigenvectors and corresponding time series. EOF is expressed as

$$
X_{m \times n}=V_{m \times m} Z_{m \times n},
$$

where $X_{m \times n}$ is a collection of spatiotemporal series with $m$ spatial dimensions that are each observed $n$ times $(t=$ $1, \ldots, t=n)$ and arrays $V_{m \times m}$ and $Z_{m \times n}$ are called empirical orthogonal functions of space and time, respectively.

Using EOF decomposition, one can obtain a set of spatially orthogonal eigenvectors from historical climate data and then expand each daily variable into its eigenvectors to obtain corresponding time series of coefficients:

$$
Z=V^{\prime} X
$$

As variable information is found mainly in the first eigenvectors, the first $p$ eigenvectors are frequently selected to approximate the overall field $[24,25]$. In addition, the predictability of EOF components decreases as their number increases [26]. Therefore,

$$
X_{m \times n} \approx V_{m \times p} Z_{p \times n} .
$$

EOF decomposition methods can be employed to obtain a set of orthogonal eigenvectors from historical climate data. A real-time variable is then projected onto the climate state base. Thus, variable temporal change is converted to changes in corresponding temporal coefficients of eigenvectors. As EOF components are sorted in descending order by variance contribution ratio, a higher EOF component ranking corresponds to a higher scale and variance contribution ratio. Therefore, STs can be obtained by selecting the EOF components with larger contribution ratios. In this study, we select the first 30 modes of the EOF to approximately represent the actual atmosphere and to conduct the numerical experiment.

Extended-range weather forecasts for the next 10-30 days are affected by initial and boundary conditions [27, 28]. Effects of external boundary conditions, such as those of sea surface temperature (SST), sea ice, and soil moisture, 


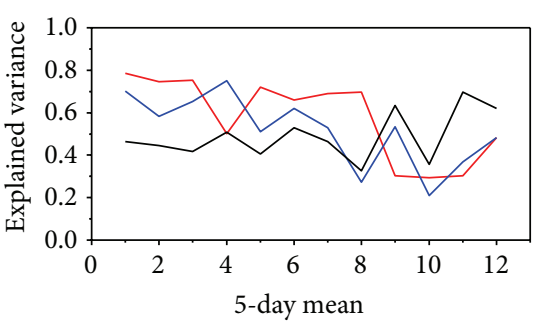

(a) Jan.-Feb.

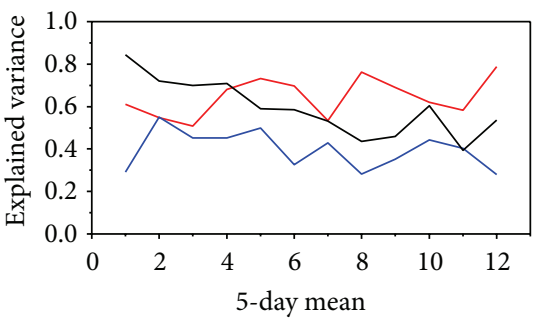

(d) Apr.-May

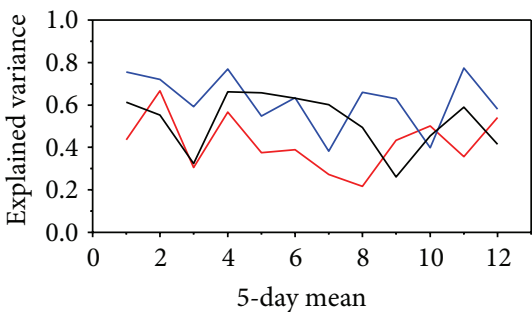

(g) Jul.-Aug.

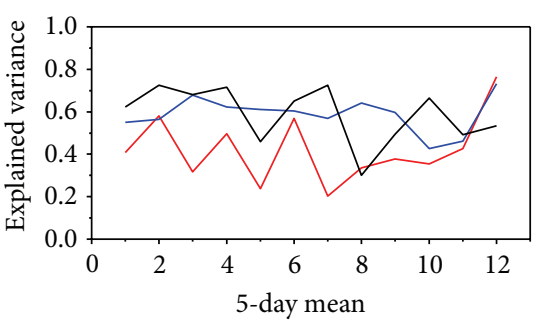

(j) Oct.-Nov.

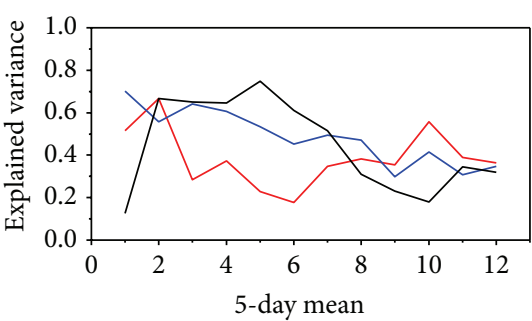

(b) Feb.-Mar.

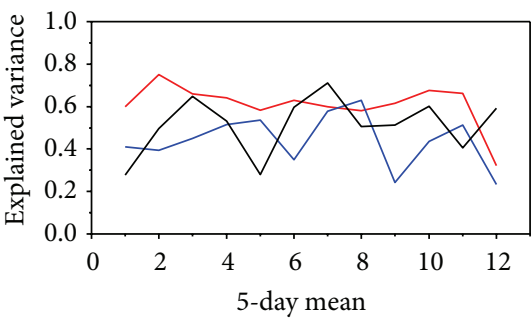

(e) May-Jun.

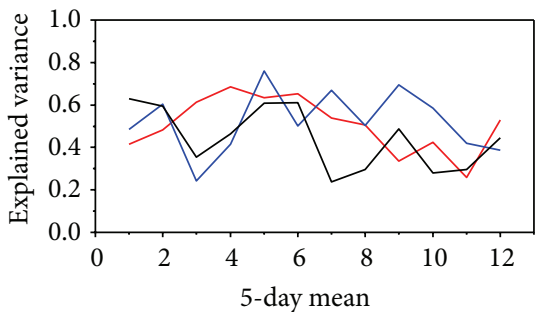

(h) Aug.-Sep.

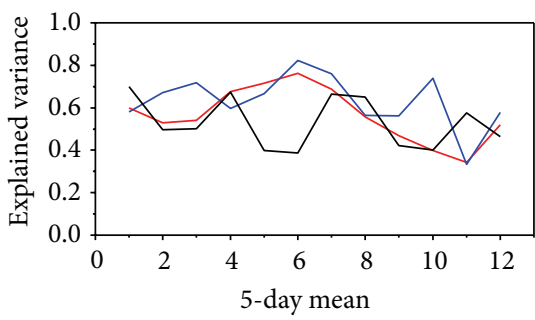

(k) Nov.-Dec.

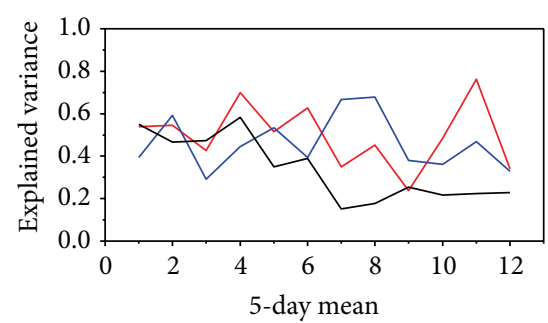

(c) Mar.-Apr.

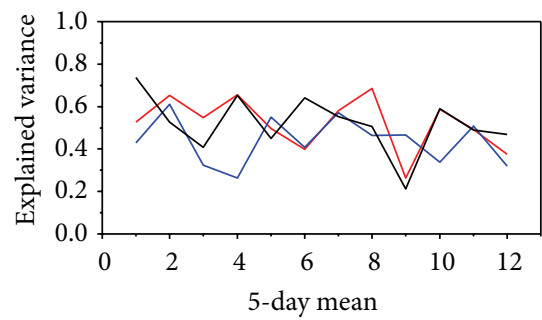

(f) Jun.-Jul.

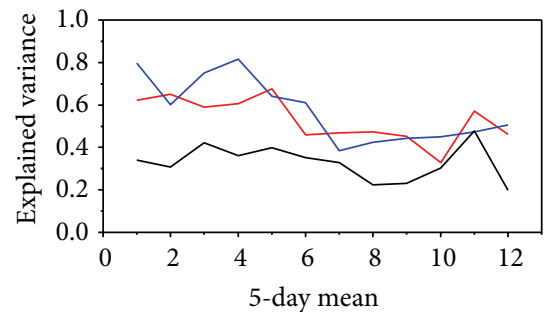

(i) Sep.-Oct.

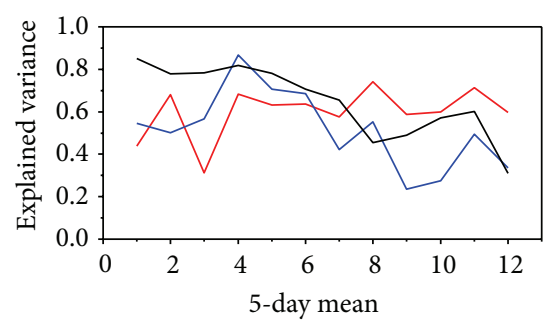

(l) Dec.-Jan.

FIGURE 1: Monthly change in the pentad average of the explained variance for 10-30-day STs of the Northern Hemisphere 500 hPa height field. The blue line denotes the La Niña year, the red line denotes the El Niño year, and the black line denotes the neutral year.

on atmospheric motion cannot be neglected [29]. Equatorial Pacific SST variations have a substantial effect on the global atmospheric circulation. The Niño 3.4 region is believed to constitute an area of the tropical Pacific where SST anomalies have the strongest influence on the global atmosphere [30-32]. Here, we only consider the influence of the eastern equatorial Pacific SST; similar to weather forecasting, significant ocean boundary-condition forcing appears after approximately two weeks; the Niño 3.4 index is used as a similar criterion to represent external forcing $[33,34]$. From historical data, 10 similar years are selected based on the Niño 3.4 index of the same period for a target month to calculate the EOF and extract the climate state base. Using January 2012 as an example, we first select historically similar daily data from January to February and obtain 10to 60-day components using a Butterworth band-pass filter.
We then decomposed the climate state base via EOF, filtered and projected the daily data for January 2012 onto the climate state base, and selected the 10 EOF components with the highest average explained variances. The duration was met or exceeded for 15 days of one month. Large-scale components with high contributions and long durations are defined as the 10-30-day STs for January. The STs are expected to exist continuously throughout February 2012, and the explained variance changes for the two months are further examined in Figures 1 and 2.

\section{Results and Discussions}

3.1. Impact of ENSO on the Transmission of 10-30-Day STs. Typical years for El Niño (1997), La Niña (2012), and neutral weather patterns (2001) were selected as representative cases 


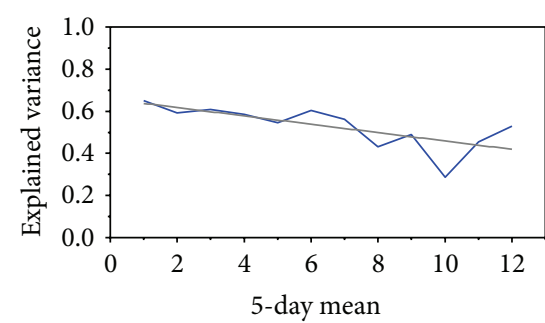

(a) Jan.-Feb.

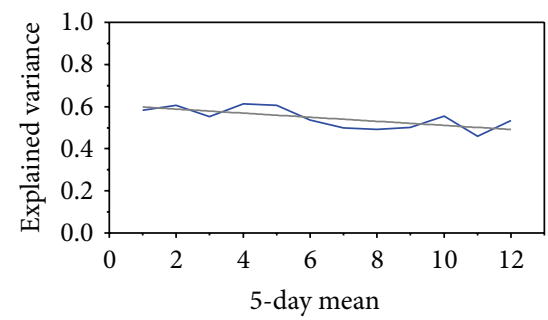

(d) Apr.-May

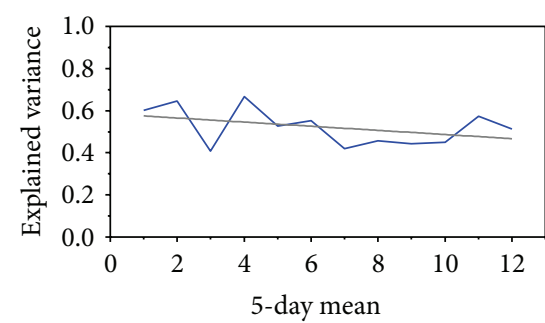

(g) Jul.-Aug.

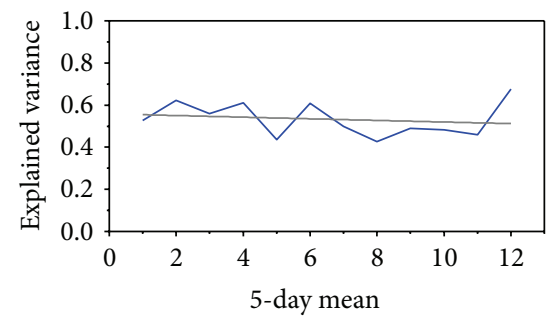

(j) Oct.-Nov.

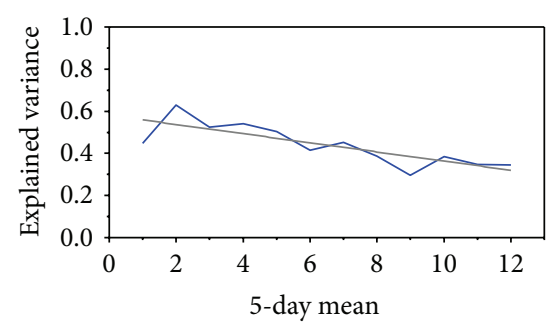

(b) Feb.-Mar.

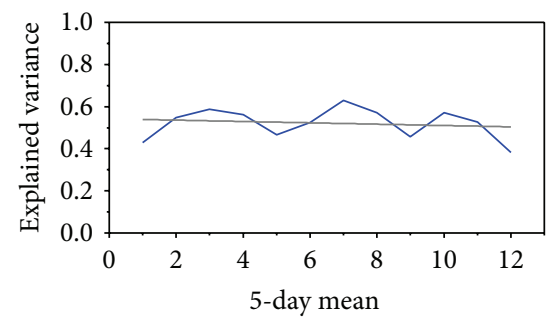

(e) May-Jun.

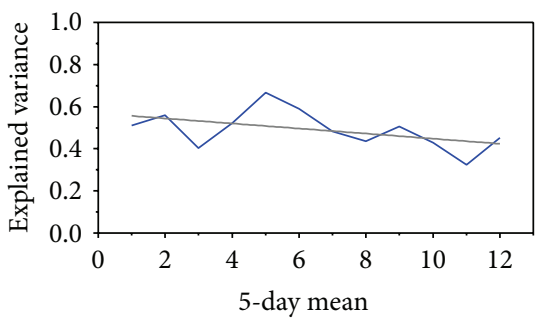

(h) Aug.-Sep.

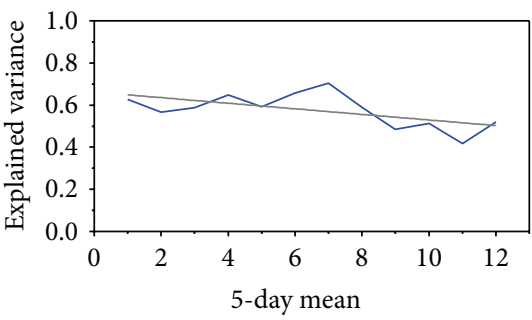

(k) Nov.-Dec.

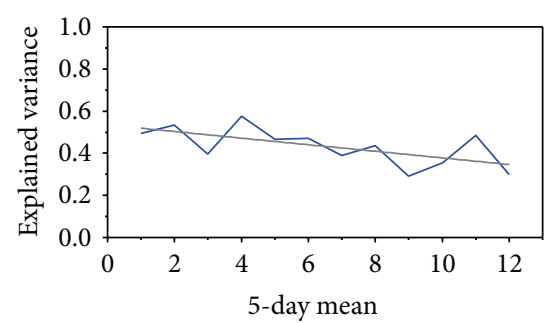

(c) Mar.-Apr.

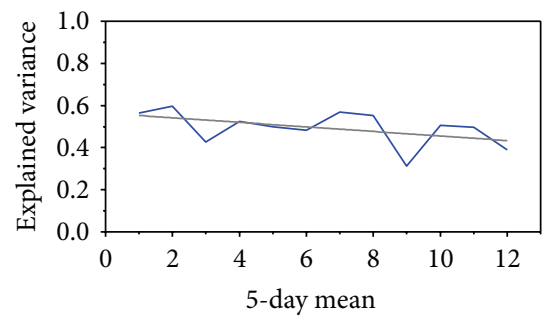

(f) Jun.-Jul.

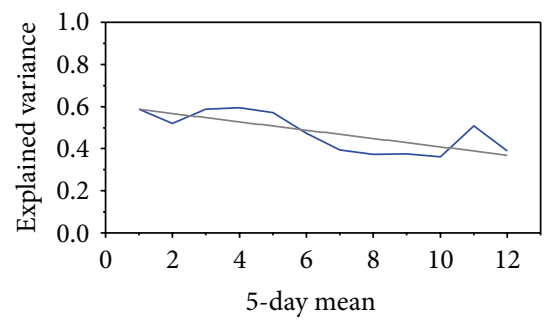

(i) Sep--Oct.

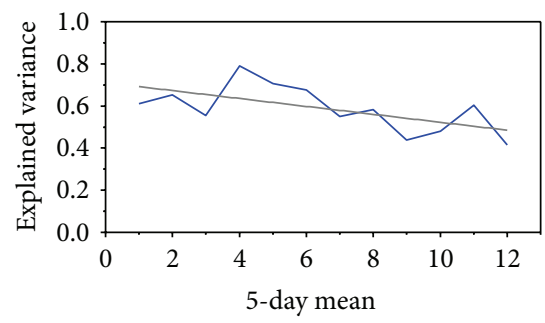

(l) Dec.-Jan.

FIGURE 2: Monthly change in the average explained variance of the three typical years' pentad averages for the 10-30-day STs of the Northern Hemisphere $500 \mathrm{hPa}$ height field. The gray line denotes the linear trend.

to examine the transfer of 10-30-day STs in the Northern Hemisphere. We calculated the monthly changes in the explained variance for every month of the three years. The results are shown in Figures 1 and 2.

Figure 1 shows that, for most time periods, the explained variance of STs is greater than 0.4 , constituting the majority of the 10-30-day atmospheric motion. Similar to other months, the explained variance differs slightly because we considered the variance contributions as well as the continuity of topranking components on a monthly scale when selecting the empirical orthogonal function (EOF) components. Therefore, if one component with high explained variance exists over a few days, then it is not selected.

A comparison between El Niño and La Niña years shows that the explained variance for STs declines slightly and the transmission attenuation trends are weaker than those of the neutral year and the continuity levels are higher in most time periods. Although the explained variances of the previous month are approximately equivalent, after one month of statistical extrapolation, the curves of the explained variance for the 10-30-day STs of the neutral year show signs of attenuation, while the attenuation patterns of the El Niño and La Niña years are relatively less significant. Therefore, stable 10-30-day components are present throughout the year. In addition, STs reflect atmospheric changes over an intraseasonal time scale and can thus characterize the overall trends of atmospheric motion.

3.2. Monthly Trends of Stable 10-30-Day Components. After synthesizing the monthly stable-component explained variances for the three study years, the overall monthly trends 
were analyzed. Figure 2 shows that, for most time periods, the trends of the explained variance are absent or slightly weakened, and the signal strength remains stable for the following months with good results. The months with highly stable levels include April-May, May-June, July-August, and October-November. The months that exhibit slight declining levels include June-July, August-September, NovemberDecember, and December-January.

Months that exhibit significant decreases include January-February, February-March, March-April, and September-October. Figure 2 clearly shows that the signal transmission is weak in February and March. Irrespective of whether the stable-component signals carry over from previous months to February and March or from February and March to the following months, the signal attenuation trends are evident. This finding may be related to patterns of seasonal transition and atmospheric circulation changes.

\section{Conclusions}

In this study, we proposed a new method for extracting 10-30-day STs from a $500 \mathrm{hPa}$ height field using historical data, and we conducted a statistical extrapolation test on an intraseasonal time scale. The results show that 10-30-day STs significantly affect synoptic processes, closely reflect monthly atmospheric changes, and characterize the overall trends of atmospheric motion.

A comparison between explained variance changes in stable 10-30-day components under various phases of ENSO shows that the transmission attenuation trends of the explained variance are weaker and more continuous than those of a neutral year. This finding agrees with the view that forecast skill strongly depends on the ENSO phase and intensity and that the skill is very poor in neutral ENSO years $[28,35]$. Given the pentad average changes in the comprehensive average explained variance, 10-30-day STs can transfer continuously and stably to the following month in most cases. STs can thus be more accurately reflected in dynamic models than other components on a 10-30-day time scale.

This method only employs historical data and initial data to extract 10-30-day STs in the atmosphere, and it facilitates the improvement of forecasting precision in combination with existing model products. However, we only conducted extraction and analysis studies for a $500 \mathrm{hPa}$ height field in the Northern Hemisphere and compared changes in various ENSO events. Consequently, additional experiments must be conducted in the future. Furthermore, additional studies should further describe 10-30-day STs through modeling.

\section{Conflict of Interests}

The authors declare that there is no conflict of interests regarding the publication of this paper.

\section{Acknowledgments}

The authors thank Bin Wang of International Pacific Research Center (IPRC) and Lian Chen of Zhejiang Climate Center for their helpful comments. This study was supported by the National Basic Research Program of China (Grant nos. 2012CB955902 and 2013CB430204), the National Natural Science Foundation of China (Grant nos. 41530531 and 41375078), and the Public Welfare Technology Research Projects of Zhejiang Province (Grant no. 2015C33055).

\section{References}

[1] E. N. Lorenz, "Atmospheric predictability as revealed by naturally occurring analogues," Journal of the Atmospheric Sciences, vol. 26, no. 4, pp. 636-646, 1969.

[2] A. Dalcher and E. Kalnay, "Error growth and predictability in operational ECMWF forecasts," Tellus A, vol. 39, no. 5, pp. 474491, 1987.

[3] J. Li and R. Ding, "Temporal-spatial distribution of atmospheric predictability limit by local dynamical analogs," Monthly Weather Review, vol. 139, no. 10, pp. 3265-3283, 2011.

[4] H. Yu, J. Huang, and J. Chou, "Improvement of mediumrange forecasts using the analog-dynamical method," Monthly Weather Review, vol. 142, no. 4, pp. 1570-1587, 2014.

[5] R. A. Madden and P. R. Julian, "Detection of a 40-50 day oscillation in the zonal wind in the tropical Pacific," Journal of the Atmospheric Sciences, vol. 28, no. 5, pp. 702-708, 1971.

[6] J. He and S. Yang, "Meridional propagation of east Asian lowfrequency mode and midlatitude low-frequency waves," Acta Meteorologica Sinica, vol. 4, no. 5, pp. 536-544, 1990.

[7] F. Y. Wei and T. Zhang, "Oscillation characteristics of summer precipitation in the Huaihe River valley and relevant climate background," Science China Earth Sciences, vol. 53, no. 2, pp. 301-316, 2010 (Chinese).

[8] J. Shukla, "Dynamical predictability of monthly means," Journal of the Atmospheric Sciences, vol. 38, no. 12, pp. 2547-2572, 1981.

[9] J. Shukla, "Predictability in the midst of chaos: a scientific basis for climate forecasting," Science, vol. 282, no. 5389, pp. 728-731, 1998.

[10] H. Wang and K. Fan, "A new scheme for improving the seasonal prediction of summer precipitation anomalies," Weather and Forecasting, vol. 24, no. 2, pp. 548-554, 2009.

[11] B. J. Hoskins and D. J. Karoly, "The steady linear response of a spherical atmosphere to thermal and orographic forcing," Journal of the Atmospheric Sciences, vol. 38, no. 6, pp. 1179-1196, 1981.

[12] M. L. Blackmon, J. E. Geisler, and E. J. Pitcher, "A general circulation model study of January climate anomaly patterns associated with interannual variation of equatorial Pacific sea surface temperatures," Journal of the Atmospheric Sciences, vol. 40, no. 6, pp. 1410-1425, 1983.

[13] S. Yang, "Enso-snow-monsoon associations and seasonalinterannual predictions," International Journal of Climatology, vol. 16, no. 2, pp. 125-134, 1996.

[14] W. Y. Chen and H. M. Van den Dool, "Atmospheric predictability of seasonal, annual, and decadal climate means and the role of the ENSO cycle: a model study, Journal of Climate, vol. 10, no. 6, pp. 1236-1254, 1997.

[15] E.-P. Lim, H. H. Hendon, and H. Rashid, "Seasonal predictability of the southern annular mode due to its association with ENSO," Journal of Climate, vol. 26, no. 20, pp. 8037-8054, 2013.

[16] H. Ren, J. Chou, J. Huang, and P. Zhang, "Theoretical basis and application of an analogue-dynamical model in the Lorenz 
system," Advances in Atmospheric Sciences, vol. 26, no. 1, pp. 6777, 2009.

[17] J. Li, C. Sun, and F.-F. Jin, "NAO implicated as a predictor of Northern Hemisphere mean temperature multidecadal variability," Geophysical Research Letters, vol. 40, no. 20, pp. 54975502, 2013.

[18] T. DelSole and M. K. Tippett, "Predictable components and singular vectors," Journal of the Atmospheric Sciences, vol. 65, no. 5, pp. 1666-1678, 2008.

[19] J. F. Chou and M. Xu, "Progresses and prospects of short-term numerical climate prediction," Chinese Science Bulletin, vol. 46, pp. 890-895, 2001.

[20] M. Kanamitsu, W. Ebisuzaki, J. Woollen et al., "NCEP-DOE AMIP-II reanalysis (R-2)," Bulletin of the American Meteorological Society, vol. 83, no. 11, pp. 1631-1559, 2002.

[21] M. Mu, J. Li, W. Duan, J. Wang, and J. Chou, "Theoretical research on the predictability of climate system," Climatic and Environmental Research, vol. 7, pp. 227-235, 2002 (Chinese).

[22] G. Feng, S. Sun, J. Zhao, and Z. Zheng, "Analysis of stable components for extended-range (10-30 days) weather forecast: a case study of continuous overcast-rainy process in early 2009 over the mid-lower reaches of the Yangtze River," Science China Earth Sciences, vol. 56, no. 9, pp. 1576-1587, 2013.

[23] K. Wang, G.-L. Feng, Y.-X. Zeng, and X.-J. Wang, "Analysis of stable components in the extended-range forecast for the coming 10-30 days in winter 2010 and 2011," Chinese Physics B, vol. 22, no. 12, Article ID 129202, 2013.

[24] Z. Zheng, J. Huang, G. Feng, and J. Chou, "Forecast scheme and strategy for extended-range predictable components," Science China Earth Sciences, vol. 56, no. 5, pp. 878-889, 2013.

[25] K. Wang, G. Feng, S. Sun, and Z. Zheng, "Study of the stable components in extended-range forecasting for the coming 1030 days during the snow storm event in January 2008," Acta Physica Sinica, vol. 61, no. 10, Article ID 109201, 2012 (Chinese).

[26] M. Déqué, "10-Day predictability of the northern Hemisphere winter $500-\mathrm{mb}$ height by the ECMWF operational model," Tellus A, vol. 40, no. 1, pp. 26-36, 1988.

[27] B. Wang and T. Li, "Convective interaction with boundarylayer dynamics in the development of a tropical intraseasonal system," Journal of the Atmospheric Sciences, vol. 51, no. 11, pp. 1386-1400, 1994.

[28] B. Wang, J.-Y. Lee, I.-S. Kang et al., "Advance and prospectus of seasonal prediction: assessment of the APCC/ CliPAS 14-model ensemble retrospective seasonal prediction (1980-2004)," Climate Dynamics, vol. 33, no. 1, pp. 93-117, 2009.

[29] Y. Lian, B. Shen, S. Li et al., "Impacts of polar vortex, NPO, and SST configurations on unusually cool summers in northeast China. Part I. Analysis and diagnosis," Advances in Atmospheric Sciences, vol. 30, no. 1, pp. 193-209, 2013.

[30] M. A. Cane, A. C. Clement, A. Kaplan et al., "Twentieth-century sea surface temperature trends," Science, vol. 275, no. 5302, pp. 957-960, 1997.

[31] N. Shi, L. Chen, and D. Xia, "A preliminary study on the global land annual precipitation associated with ENSO during 19482000," Advances in Atmospheric Sciences, vol. 19, no. 6, pp. $993-$ 1003, 2002.

[32] J. He, J. Yu, and X. Shen, "Impacts of SST and SST anomalies on low-frequency oscillation in the tropical atmosphere," Advances in Atmospheric Sciences, vol. 24, no. 3, pp. 377-382, 2007.

[33] Z. Liu, Z. Lu, X. Wen, B. L. Otto-Bliesner, A. Timmermann, and K. M. Cobb, "Evolution and forcing mechanisms of El Niño over the past 21,000 years," Nature, vol. 515, no. 7528, pp. 550-553, 2014.

[34] M. A. Alexander, I. Bladé, M. Newman, J. R. Lanzante, N.-C. Lau, and J. D. Scott, "The atmospheric bridge: the influence of ENSO teleconnections on air-sea interaction over the global oceans," Journal of Climate, vol. 15, no. 16, pp. 2205-2231, 2002.

[35] E. K. Jin, J. L. Kinter III, B. Wang et al., "Current status of ENSO prediction skill in coupled ocean-atmosphere models," Climate Dynamics, vol. 31, no. 6, pp. 647-664, 2008. 


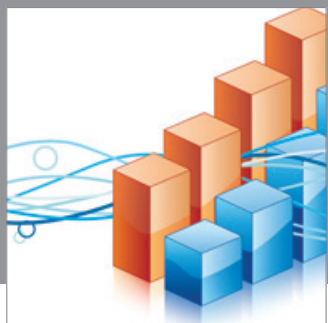

Advances in

Operations Research

mansans

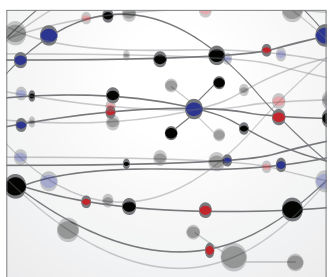

The Scientific World Journal
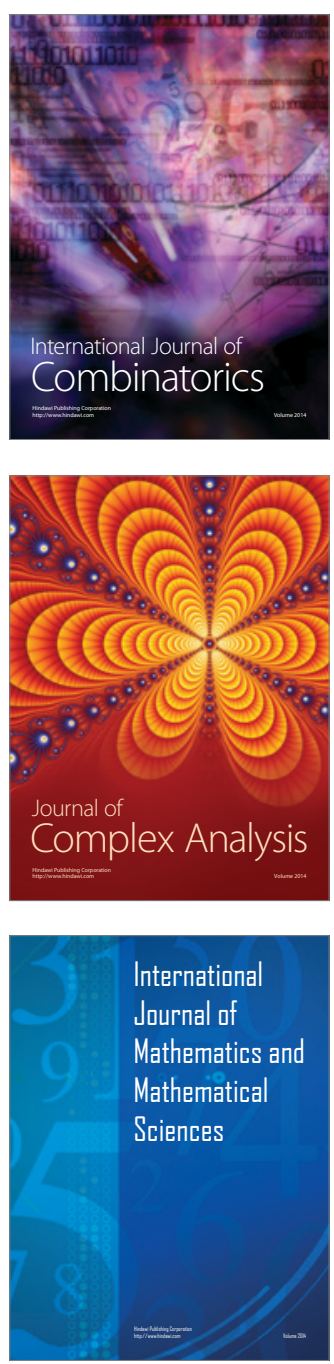
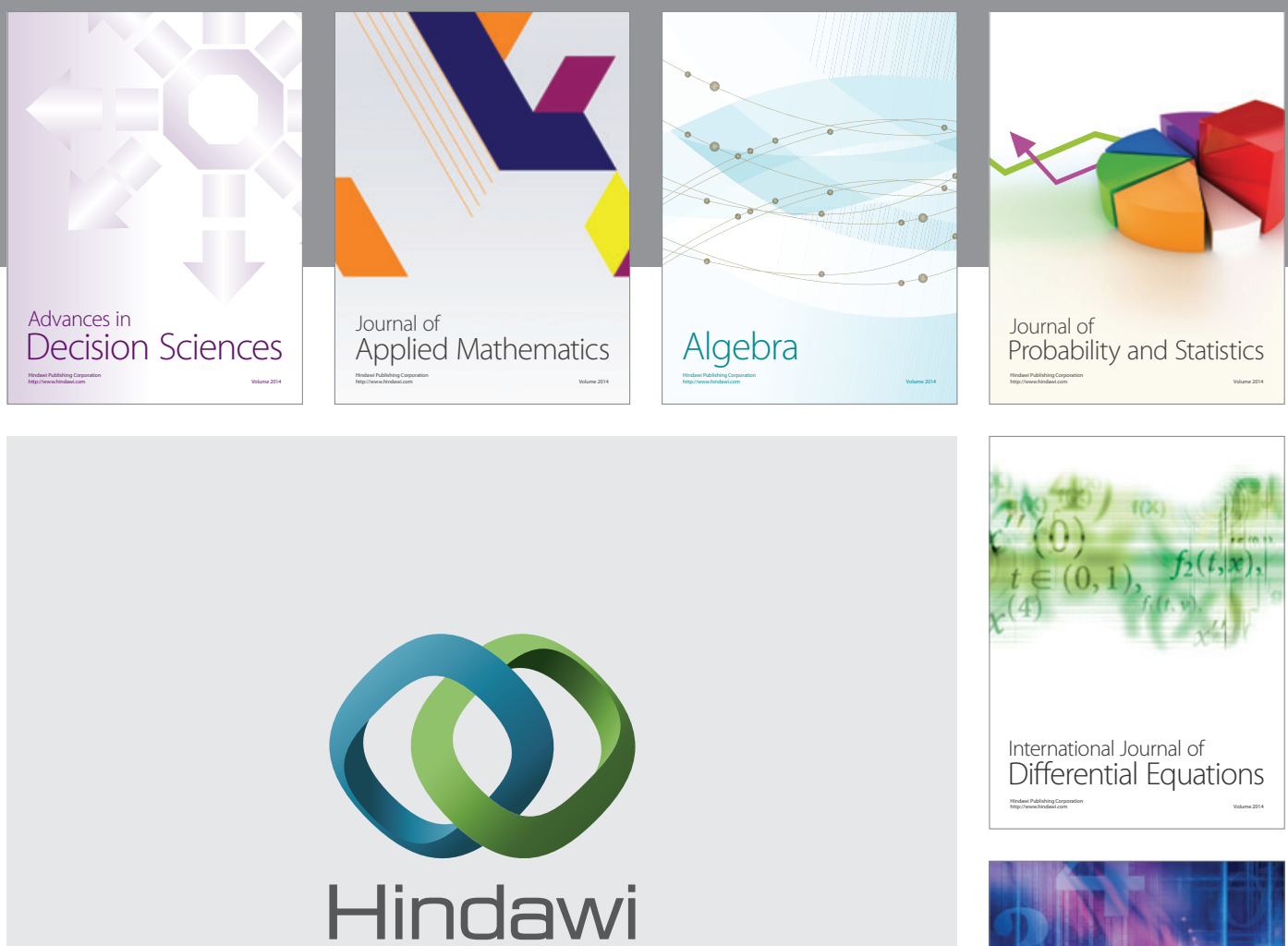

Submit your manuscripts at http://www.hindawi.com
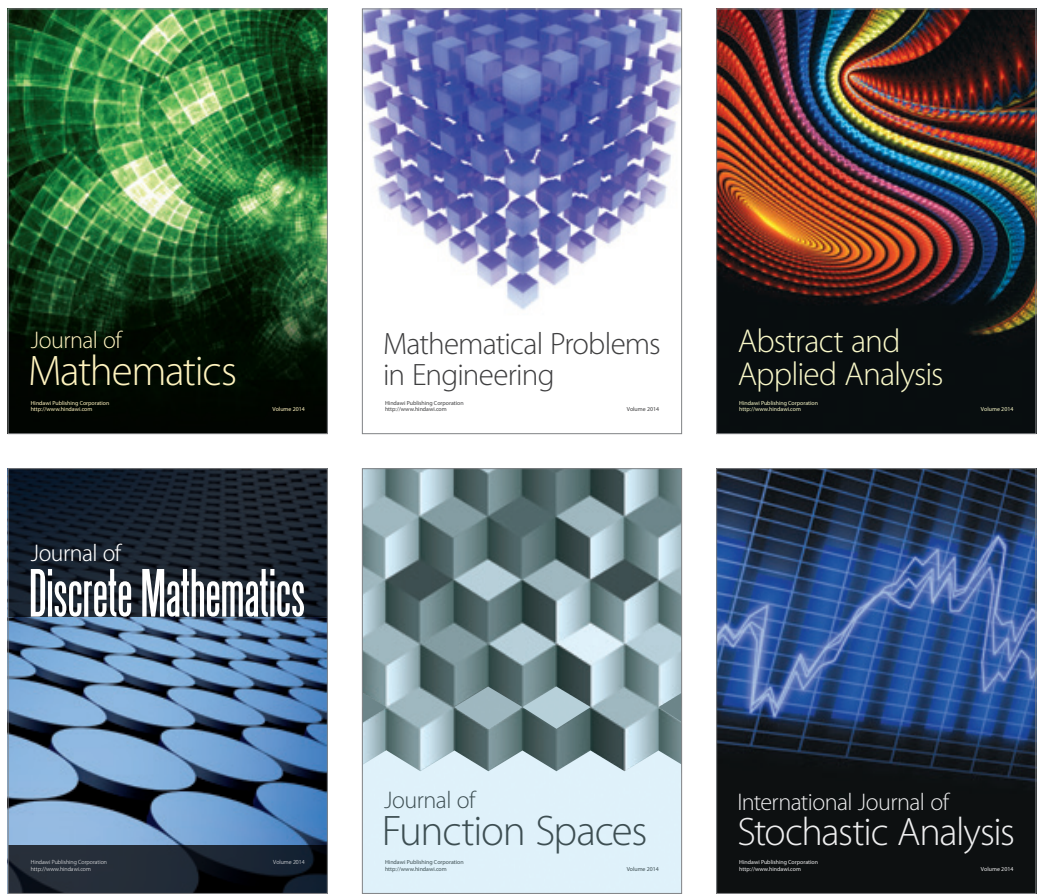

Journal of

Function Spaces

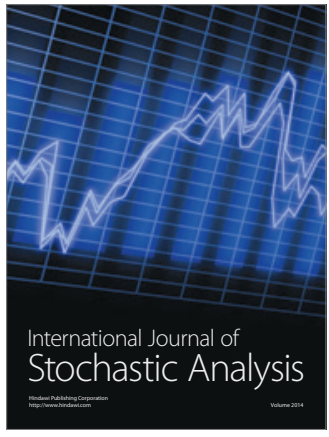

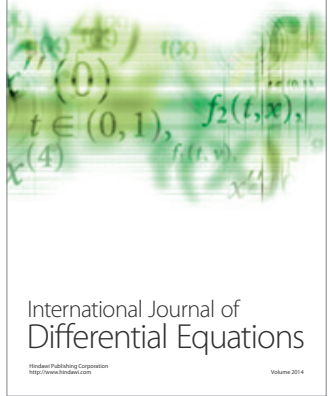
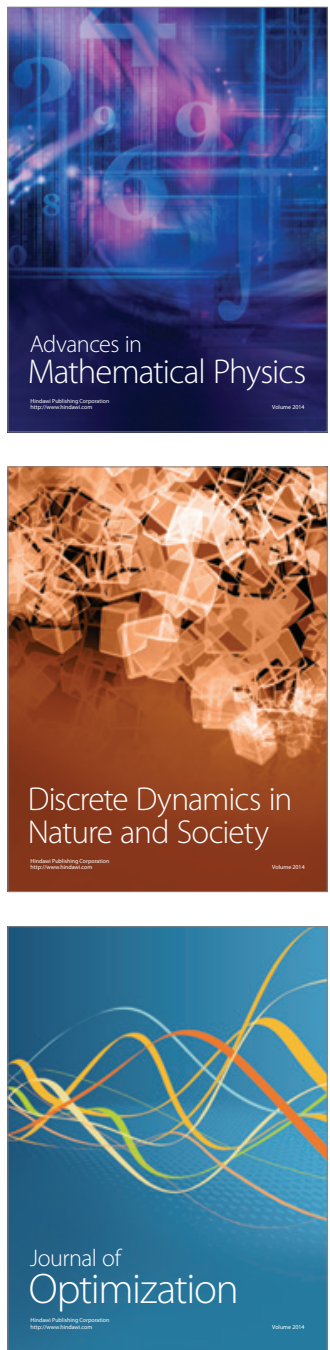